\title{
Coming to terms with Fukushima disaster-related trauma and earlier trauma by constructing a new identity. About a case
}

\author{
A. Hori ${ }^{*}$ \\ Department of Psychiatry, Hori Mental Clinic, Minami-soma, Fukushima, Japan.
}

Received: 24 September 2020 / Accepted: 26 November 2020

\begin{abstract}
The incidence of post-traumatic stress disorder, depression, and anxiety generally increases after disasters, and the 2011 Great East Japan Earthquake and nuclear power plant accident were no exception. Psychological first aid providers who deliver interventions to address mental health issues do not emphasize psychiatric expertise, but instead go into the field to help residents rebuild and stabilize their daily lives and provide a link between them and supporters. When psychiatric problems do not improve with such interventions and persist for more than a few years, specialized psychiatric interventions are considered. Past studies have examined the experience of prolonged exposure therapy (a specialized cognitive behavioral therapy for post-traumatic stress disorder) among survivors of the Fukushima nuclear power plant accident. The participant in this study was a survivor who was evacuated from the nuclear power plant accident but had experienced multiple traumas and had been a victim of domestic violence before the disaster. Recovery in this case did not involve a simple psychiatric treatment for trauma, but rather a process of overcoming the values that caused indulgence in victimization to form a new identity.
\end{abstract}

Keywords: dwelling / health impact / nuclear accident / professional ethics / treatment

\section{Introduction}

Victims of nuclear accidents experience significant psychological impact. The most significant public health impact of the 1986 Chernobyl disaster was identified as the psychological effect of the accident (Bromet et al., 2011; Bromet, 2012). A survey of the affected population found high rates of clinical and subclinical depression, anxiety, and posttraumatic stress disorder (PTSD) (Bromet, 2012). In a survey of residents evacuated by evacuation order after the nuclear accident in Fukushima, the rates of suspected PTSD were $19.0 \%$ at 10 months and $17.8 \%$ at 35 months for men and $25.3 \%$ and $23.3 \%$ at 10 months and 35 months for women (Kukihara et al., 2014; Maeda and Oe, 2017). In addition, the rate of depression among evacuated residents of Fukushima was estimated to be $14.6 \%$ in $2012,11.9 \%$ in 2013 , and $9.3 \%$ in 2014 (Oe et al., 2016; Maeda and Oe, 2017).

Depression and PTSD are known to increase after other types of disasters as well. For example, surveys conducted 14, 30,43 , and 54 months after the earthquake and tsunami off the coast of Miyagi Prefecture, which was less affected by the nuclear accident but severely affected by the Great East Japan Earthquake, found that $62.7 \%$ of medical personnel and

*Corresponding author: arinobu.h@gmail.com government officials in the coastal areas of Miyagi Prefecture demonstrated resistance to PTSD symptoms, 24.3\% had subsyndromal symptoms and $6.3 \%$ were recovered. However, $3.5 \%$ had fluctuating symptoms and $3.2 \%$ had chronic symptoms (Sakuma et al., 2020) suggesting that they needed treatment.

On the other hand, a study on the rates of suicides related to the Great East Japan Earthquake up to 2017 found that the disaster-related suicide rate, which increased after the disaster in Iwate, Miyagi, and Fukushima prefectures, which were severely affected by the disaster, decreased in Iwate and Miyagi prefectures where the impact of the nuclear accident was small, but not in Fukushima prefecture (Takebayashi et al., 2020). In addition, a cohort study of Estonians who were cleanup workers after the Chernobyl disaster found an increase in suicide rates among the group compared with the general population, even 17 years after the disaster (Rahu et al., 2006). These findings suggest that although other disasters also have a significant impact on the mental health of the victims, nuclear accidents have a longer and more severe impact.

Residents involved in a nuclear accident are required to make a number of important decisions at different times. The biggest one will be whether to evacuate. They will have to make decisions about the basic aspects of their lives, including the environment in which they will live and the food they will eat. Consensus building among stakeholders is very important 


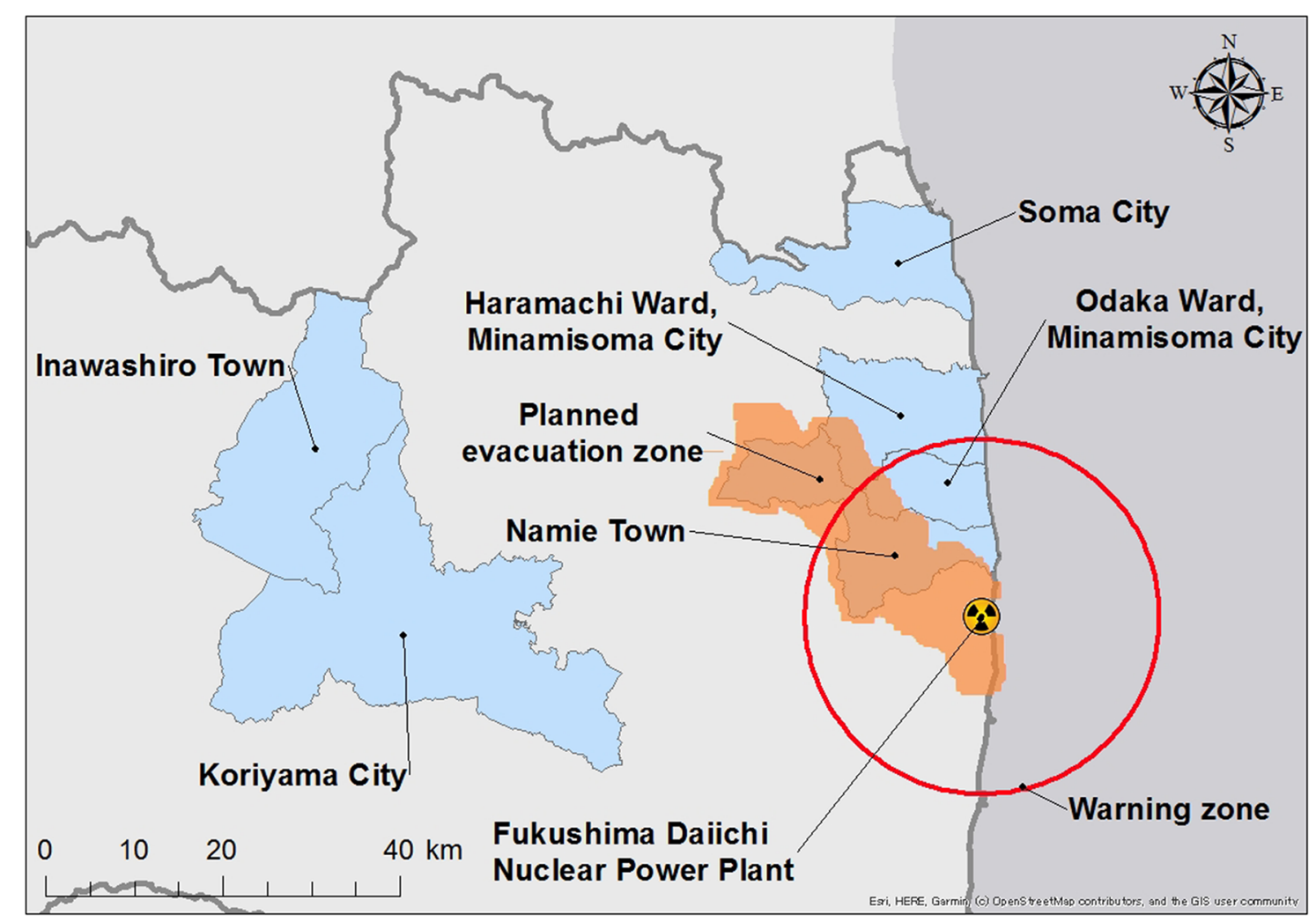

Fig. 1. The municipalities associated with this case.

in deciding the type of environment in which they will live. The prerequisite for such discussions is a healthy mind, but, as mentioned above, a certain percentage of the residents are likely to have mental health problems after the accident.

Intervention studies that promote improvement in the mental health of the affected population may be important to reduce distress and loss and to support better decision-making in complex situations. North and Pfefferbaum (2013) reviewed the research on post-disaster interventions for mental problems and recommended less-invasive interventions such as psychological first aid (PFA) (National Child Traumatic, 2006; World Health Organization, 2011; Edward and Davis, 2012) immediately after a disaster. The main objective of PFA after a disaster is to provide practical assistance for coping with difficult living situations, such as ensuring physical safety and restoring connections among people. Trauma-focused cognitive behavioral therapy is only recommended for patients who are struggling with disaster-related traumatic memories even after the use of interventions such as PFA (North and Pfefferbaum, 2013). The critical incident stress debriefing (Mitchell, 1983), which encourages patients to talk about their traumatic memories in the acute post-disaster period, is currently of questionable effectiveness and is not recommended (van Emmerik et al., 2002). As mentioned above, a survey of the general population in Fukushima Prefecture after the nuclear accident showed an increase in depression and other symptoms, but the number of visits to psychiatric institutions in Fukushima Prefecture for depression actually decreased in 2011 (Hori et al., 2016). Against this background, systematic interventions to address mental health issues after disasters are difficult to implement.
Despite the limitations of post-disaster research, we reported a post-disaster PTSD patient to whom we have used prolonged exposure (PE) therapy (Foa and Kozak, 1986), a trauma-focused cognitive behavioral therapy with a growing body of evidence on the efficacy (Hori et al., 2019). In the present study, we also report the case of a patient with postdisaster PTSD who was treated with PE (Foa and Kozak, 1986), but the process was more complicated. The patient's symptoms were related not only to the trauma of the disaster but also to the trauma experienced during the post-disaster evacuation period and problems of domestic violence that existed before and after the disaster. Recovery was not simply a matter of ameliorating symptoms, but also of overcoming old values, constructing a new identity, and renewing relationships. This recovery of the individual is a prerequisite for the recovery of the whole community and consensus building through the participation of the people in the true sense of the word.

\section{Materials and methods}

The author is a psychiatrist who lived in Tokyo before the Great East Japan Earthquake. Since April 2012, he has been living within $20-30 \mathrm{~km}$ of the crippled nuclear power plant in Minamisoma (Fig. 1), Fukushima Prefecture. Since 2016, he has operated his own mental health clinic in Minamisoma City (Fig. 1), outside the $30-\mathrm{km}$ radius of the nuclear power plant. The case reported here is one in which the author became involved as an attending physician while working at a psychiatric hospital and has since continued to treat the patient 
at his own clinic. As a result of support from the Japanese government for the victims, the patient and her family continue to be exempt from paying medical expenses.

The author's clinic uses PE therapy (Foa and Kozak, 1986), a cognitive behavioral therapy for PTSD. Sessions are 90 minutes in length and are often conducted once a week for a total of 6 to 20 sessions. The treatment program included psycho-education on the symptoms of PTSD and training in breathing techniques. The Subjective Units of Discomfort Scale (SUDS), a tool for measuring the intensity of emotions such as fear and distress that is experienced at the time of measurement, was used in this study. The level of intensity is expressed as a specific number, which ranges from 0 to 100 . After patients understand the SUDS, they perform the exposure technique, gradual exposure to avoided stimuli, which makes patients recall their traumatic memories. At this time, it is not therapeutically desirable for the intensity of the emotional stimuli to be either too strong or too weak for the patient to experience. It is important that the patient's distress from exposure to traumatic stimuli is maintained within an appropriate range, and the SUDS is used as a reference for this purpose. There are two types of exposure techniques: reality exposure and imaginary exposure. Reality exposure is a gradual exposure to a real situation that is avoided when, for example, a person affected by a tsunami is not allowed to go to the sea or a person affected by a car accident is not allowed to go to the scene of an accident. Imaginary exposure is the deliberate recall and recounting with the therapist of memories about the trauma that are painful to recall. Prolonged exposure therapy is designed to habituate patients to avoided trauma stimuli through repeated exposure to the stimuli carried out in an appropriate manner. This form of therapy involves a process of exposure to trauma stimuli, in which trauma memories are reviewed and discussed in terms of their meaning and value to the individual. The Post-traumatic Diagnostic Scale (Foa et al., 1997), a measure of the intensity of trauma response, and the Beck Depression Inventory, second edition (Beck et al., 1996), a measure of the intensity of depressive symptoms, were administered at the beginning of each session.

Written consent to report this case was obtained from the patient.

\section{Case description}

The patient was a housewife in her early 40s when the Great East Japan Earthquake struck.

Diagnosis: PTSD, dissociative disorder.

She was born in the town of Odaka, Minamisoma (Fig. 1), and married into a fisherman's family on the coast of Namie Town in her 20s (Fig. 1). Until the earthquake, the patient herself worked as a housewife at home and also helped the fishermen with their work. She gave birth and raised two children while caring for her grandparents-in-law and parentsin-law. She has been exposed to constant violence and verbal abuse, especially from her grandmother-in-law, and experienced verbal abuse and intimidation from her father-in-law.

When the earthquake and tsunami struck in 2011, her house, which was a fisherman's house, was completely washed away. The entire municipality in which she lived was forced to evacuate due to the nuclear accident, and she had to remain evacuated for years afterward. Had it not been for the nuclear accident, she could have returned and rebuilt her home earlier. Victims of the Great East Japan Earthquake received compensation from the government, and more money was paid out to those whose daily lives were more severely affected by the nuclear accident. Because she was ordered to evacuate, she received more compensation than victims in areas where the evacuation order was not issued. People in areas where mandatory evacuation orders were issued were sometimes envied by those in areas where they were not, and this was the case for her family too. However, her house and the surrounding area near the sea had lower radiation levels after the accident, so she received less compensation than the victims in the higher radiation level areas, a complicated and difficult situation for others to understand.

\section{History of trauma}

\subsection{Domestic violence before the earthquake}

More than 10 years before the earthquake, the patient's father died of gastric cancer. In addition, her mother-in-law, who had been the primary caregiver for her grandmother-inlaw who had dementia, died, and the patient was left to deal with the care of her grandmother-in-law. Although her motherin-law, who died early, was a calm person, the patient frequently witnessed violence being inflicted on her mother-inlaw by her father-in-law. There was also constant verbal abuse and violence from the grandmother-in-law to the patient herself. Her father-in-law forced her to help him launch his boat to go fishing in the early morning. In addition to taking care of her grandmother-in-law, she worked part-time to support her daughter's schooling, and she was forced to work on her father-in-law's boat every day. Her grandmother-in-law also died before the disaster. Her husband's intervention in this matter was limited. The bullying she received from her grandmother-in-law was so severe that she tried to commit suicide by hanging herself while having what appeared to be dissociative symptoms and was rescued by her dog.

\subsection{Effects of the earthquake}

The patient experienced the effects of the Great East Japan Earthquake at her home near the coast. The ground in the garden was cracked. She went upstairs to bring her dog even though her father-in-law was complaining about it. Desperate to escape the tsunami, she drove with her family to her sister's house in the mountains away from the sea. The fact that they had practiced evacuation in the event of a tsunami on a regular basis came in handy. Many of her son's classmates and acquaintances had died. Her home was swept away and destroyed completely by the tsunami.

\subsection{Life after evacuation}

After the earthquake, she moved repeatedly and experienced life in seven different places. The gymnasium that was used as a shelter immediately after the earthquake was partitioned with only cardboard boxes. After that, she moved to a hotel in Koriyama City (Fig. 1), where pets are allowed and 
lived there for 1 month. She stayed at a shelter in Inawashiro City (Fig. 1) for 6 months, where she developed high blood pressure and began to experience stomach pain. At the end of 2011, while she was living in this temporary housing, she was found to have gastric cancer and had a total resection of her stomach. After the surgery, she developed dumping syndrome and had to eat six separate meals a day. Next, she lived in temporary housing in Soma City (Fig. 1) for about 4 years.

\subsection{Current medical history}

In early 2014, doctors found that her father-in-law had cancer, and the patient, who accompanied him to the hospital, was informed by the doctor. Her father-in-law underwent an operation, and immediately afterward, he became delirious, and the hospital requested that his family members attend to him 24 hours a day. There was an episode in which her fatherin-law, who was suffering from delirium at that time, hit her hard in the hospital intensive care unit. The patient began to experience headaches and other problems and began visiting the physician's office. Despite this condition, she continued to take care of her father-in-law by preparing meals for him and accompanying him to hospital visits. Although her father-inlaw himself did not remember hitting the patient because he was delirious, people around him did not tell her father-in-law that he had hit the patient, out of concern for his emotions. She started to have a major hyperventilation attack and was admitted by ambulance to a psychiatric hospital for one night. The author has been the attending physician since that time. After that, she continued to receive outpatient treatment. Frequent dissociative symptoms, such as amnesia, were observed. Next, she moved out of temporary housing in Soma City and began living in a rented house in Haramachi, Minamisoma City (Fig. 1). She became unstable and repeatedly suffered hyperventilation attacks when she heard neighbors, saying that the reason she was not working was because she was receiving compensation and that they were going to build a bigger house and move out sooner or later. "If it hadn't been for the nuclear accident caused by Tokyo Electric Power Company (TEPCO), this wouldn't have happened", she said. It seemed to the patient that people in Minamisoma's Haramachi Ward (Fig. 1) believe that because the mandatory evacuation order was not implemented at the time of the disaster, the compensation payments ended more quickly for them than their counterparts in Namie Town (Fig. 1), which was subject to the mandatory evacuation order. However, the only compensation she received was for the evacuation of her house as a result of the disaster. Most of the damage was caused by the tsunami and compared with those who were directly affected by the nuclear accident, she had less security for her life, and felt very nervous. She was told by neighbors that it would be good because she was receiving monthly compensation for the mandatory evacuation order. Finally, she built a house in Haramachi Ward, Minamisoma City (Fig. 1), and moved out of a rented house. It was at this time that she was shocked to be told that she was lucky to have a nice house built (with compensation money). In addition, her father-in-law would complain about the relocation, and she would shake all over when her father-in-law would say things strongly to her. At that time, her daughter gave birth to her grandson. Taking care of her grandson offered the patient support and comfort. Her father-in-law's general condition worsened and he had to be admitted and discharged from the hospital repeatedly because he did not restrict salt intake even though he had renal dysfunction, but she often escorted him to the hospital despite the patient's great distress. Eventually, her father-in-law started dialysis. At that time, her mother, who had been living in temporary housing after the earthquake, moved into her neighborhood. Having her mother in the neighborhood provided her with a great source of support.

\section{Implementing prolonged exposure therapy}

Because the patient refused to talk about her trauma and domestic violence for a while after the start of treatment, and her symptoms (mainly panic attacks) were severe, the author tried to alleviate her anxiety symptoms with supportive measures and medication in the form of anxiolytic drugs, selective serotonin reuptake inhibitors, and a small amount of antipsychotic drugs. It became clear that her father-in-law's repeated verbal threats caused her symptoms to become unstable. As her condition worsened, she recalled the memory of people around her gossiping about the compensation she had received. They believed evacuees were "sucking the good soup", and she was unable to go outside her house. Eventually, it was discovered that she had frequent symptoms of PTSD with flashbacks of her father-in-law striking her on the head at the time of his surgery. Nevertheless, she would accompany his father-in-law during hospital visits and spend time with him in a greasy sweat for 4 to 5 hours. While she was in the middle of remembering what happened in the earthquake and tsunami in order to prepare a document to compensate for the accident at TEPCO, she began to have dissociative symptoms and started talking about things that made no sense, and she lost her memory of that time. Medication alone did not provide adequate control of the anxiety symptoms, and the introduction of PE therapy was considered.

One concern with regard to the introduction of the therapy was whether the living environment at the time the trauma-focused psychotherapy was being implemented was sufficiently safe. The party who hit the patient continued to live with her while maintaining an intimidating attitude and there was a risk that he would not be able to cope with the patient's worsening symptoms during the course of the psychotherapy. However, at that point in time, the patient's situation had become critical due to frequent panic attacks and dissociative symptoms. She and her family were refusing to seriously consider separation or divorce, and she was able to obtain the full understanding and cooperation of her husband and other family members, mainly her own mother, who lived in the neighborhood. Therefore, it was decided to implement PE therapy. Just prior to the implementation of this treatment, the patient expressed the desire to return to her old self again.

\subsection{Implementing prolonged exposure therapy}

A total of 15 sessions of PE therapy, a cognitive-behavioral therapy for PTSD, were administered once a week. After treatment, the Beck Depression Inventory, second edition score 
decreased from 40 to 25 points, and the Post-traumatic Diagnostic Scale score decreased from 31 to 8 points.

\subsubsection{Session 1}

The patient was asked to recount details from her father-inlaw's cancer diagnosis as well as details of his delirium and beatings after surgery. In the course of recounting the details, she recalled another traumatic memory of being abused by her grandmother-in-law and attempting to commit suicide by hanging herself. At this time, she recalled an episode in which her dog barked, which led to her recovery from dissociative symptoms and saved her own life.

\subsubsection{Session 2}

When looking at the face of her father-in-law, who lived with her, her Subjective Units of Distress Scale would rise to $80-90$ (100 being the highest score). She practiced getting used to hearing her father-in-law's "coughing".

\subsubsection{Session 3}

She recorded her father-in-law on her smartphone and practiced viewing him. It was observed that she frequently hyperventilated spontaneously in the closed bathroom at home.

\subsubsection{Session 4}

She practiced looking at the picture of her father-in-law from the front.

\subsubsection{Session 5}

The patient recalled and discussed the experience of being struck in the head by her father-in-law. After only one session, habituation to recalling this memory occurred and anxiety about recalling it was reduced. It was evident that there were many other experiences that were similarly traumatic.

The total number of traumatic memories addressed during the treatment was six. The six traumatic memories were as follows: being struck in the head by her father-in-law; a patient in the same room as her father-in-law suddenly dying; her own father's death as a result of cancer; having cancer herself and undergoing surgery; being abused by her grandmother-in-law and the suicide attempt; and the earthquake, tsunami, and initial evacuation during the disaster.

\subsubsection{Session 6}

She recalled the moment when a patient in the same room as her father-in-law suddenly died.

\subsubsection{Session 7}

She recalled the memory of her father's death from gastric cancer. The patient said afterward that it was quite hard to think of this part of her life and she was sick for a week.

\subsubsection{Session 8}

As a continuation of session 7, the patient recalled and recounted the scene of her father's death. At this time, the patient recounted how she experienced her first hyperventilation attack and fainting.

\subsubsection{Session 9}

As an imaginary exposure, she recalled and talked about how she had gastric cancer. A period of time existed when she remembered her father's death and feared that she was going to die too.

By session 9, she had little or no fear of looking at the picture of her father-in-law from the front, which she had practiced. She was now mentally strong enough to leave the house on her own for about 30 minutes per day.

\subsubsection{Session 10}

The patient recalled memories of her grandmother-in-law. The grandmother had become paranoid due to her dementia and told relatives that she was bullied by the patient. In fact, however, the opposite was true; for example, whenever the patient tried to get her grandmother-in-law to change clothes, her grandmother-in-law would pull her hair or scratch her and once scarred her for 2 years. At this time, the patient also recounted the episode at home where she became dissociative and attempted suicide, but her dog barked, and the dissociative symptoms subsided, and her life was saved. This memory caused the most intense fear felt by the patient throughout the entire course of treatment.

\subsubsection{Sessions $11-13$}

The patient continued to recall the memories of her grandmother-in-law. This part of the story was found to be the traumatic memory that had the greatest impact on the patient and caused the most intense fear. However, when the patient refused to recall the scene in which she had nearly committed suicide by hanging herself before repeated imaginary exposures provided habituation, we stopped working on this part of the story. She also talked about how she had once harbored feelings of hatred for her grandmother-in-law and her husband who had not helped her in that situation. However, she now felt closer to her husband, who was concerned about her current condition. At this point in her treatment, she no longer felt fearful of seeing her father-inlaw in person.

\subsubsection{Session 14}

She recalled her experiences in the early days of the tsunami and evacuation in the aftermath of the Great East Japan Earthquake. It was difficult to find a place that would accept her and her dog, but she could not imagine leaving her dog, who had saved her life, behind. The patient and her family were told that they would be accepted if they went to Koriyama City, so they went there, but they were shocked when they were first treated like mold during the screening phase. They were moved to a community center that was used as a shelter, but they felt fearful because of the strict attention given to the patients' families. In the end, her dog was not accepted, and they had to move elsewhere. During the processing part of the therapy, she made the following comments: "There's so much going on, I just don't know what it is.", "It's sad to remember. 
Table 1. Traumatic events and situations experienced by the patient.

\begin{tabular}{|c|c|c|}
\hline & Problems that existed before the disaster & Problems that occurred after the disaster \\
\hline $\begin{array}{l}\text { Problems experienced by } \\
\text { the community as a whole }\end{array}$ & $\begin{array}{l}\text { 8. A trend of disdain for women } \\
\text { 9. A strict seniority system } \\
\text { 10. Community exclusivity }\end{array}$ & $\begin{array}{l}\text { 10. Earthquake } \\
\text { 11. Tsunami } \\
\text { 12. Health hazards related to the nuclear power } \\
\text { plant accident } \\
\text { 13. The harshness of living in an evacuation } \\
\text { 14. Radical changes in living conditions } \\
\text { 15. Facing jealousy over possible compensation }\end{array}$ \\
\hline
\end{tabular}

It's all gone.", "I couldn't get the thought of dying out of my mind until I was treated like this, but it's improved."

\subsubsection{Session 15}

In the final PE therapy session, the patient once again recalled her father's death, her grandmother-in-law's abuse, the earthquake, her own gastric cancer, her father-in-law's cancer and delirium, and the sudden death of another patient in her father-in-law's room. At the end of the session, she shared her thoughts about the therapy, saying that she had not thought that her condition was this serious when she started PE therapy.

She continued to have hyperventilation attacks in response to her father-in-law's threatening attitude. The period of time when she was mainly afraid continued for a long time, but gradually she started to talk back to her father-in-law in a state of dissociation from his words. She left her home for 2 months because of her rebellion against her father-in-law and lived with her mother for the first time. At this stage, her husband told his father (i.e., her father-in-law) that he had struck her in the intensive care unit and urged him to pay attention to her. The patient continued to become increasingly affected by her father-in-law's attitude. She was increasingly supported by the care of her grandchildren and the care she received from her own mother. Gradually, her husband's attitude changed to become more cooperative and he became more protective of the patient and willing to confront his father. She was able to cope with the event of separation by focusing on her eldest son's marriage. However, episodes of panic attacks and dissociative symptoms increased again due to the death of her dog and the second episode in which her father-in-law, whose authority in the household had been shaken, hit the patient for the second time, and so episodes of leaving home and living with her own mother appeared again.

\section{Discussion}

The patient had severe PTSD following the Great East Japan Earthquake and nuclear accident, but at the initial stage of her treatment, her PTSD was not fully recognized. Although the introduction of intensive treatment in this case allowed us to get a fuller picture of her condition, it cannot be denied that there may be other patients with PTSD in the community who do not primarily complain of traumatic reactions to trauma that have been overlooked. This is an area that warrants further investigation.

\subsection{Therapeutic measures}

The patient presented with severe panic attacks and dissociative symptoms that did not improve sufficiently with supportive responses and medication alone, and a traumafocused psychotherapy led to symptom control. As treatment progressed, it became clear that the patient had experienced multiple traumatic experiences before the disaster. The experiences were categorized along two axes: problems that existed before the disaster/occurred after the disaster, and problems caused by personal circumstances/experienced by the community as a whole, as shown in Table 1.

Table 1 does not list any direct health risks from radiation exposure. This is because, during this study, the patient never mentioned the threat of direct health effects from radiation exposure, but repeatedly talked about the distress experienced as a result of the evacuation and deterioration of human relationships due to suspicion and resentment over compensation payments. Hori et al. reported on a case of a municipal employee who developed PTSD and bipolar disorder after the Great East Japan Earthquake and, for that case, there was also no mention of the direct health effects of radiation. The authors attributed this to "the fact that residents who choose to live in relatively close proximity to the accident site can be seen as a biased group that does not take the possible damage of radiation exposure seriously. It is also possible to think that a manic avoidance of anxiety may be at work here. Alternatively, it could be an outcome of the risk communication that took place after the disaster" (Hori et al., 2020). This explanation would apply to the present case as well.

For "problems that existed before the earthquake due to personal circumstances", if the effects of the problems are still present at the time of treatment, psychotherapy based on the theme of trauma and grief is appropriate. Prolonged exposure therapy was carried out in this case, and was effective.

Next, with regard to "problems caused by personal circumstances and triggered by the earthquake", the first goal is to solve the practical problems. In response to the "violence by the father-in-law" (problem 4), countermeasures such as 
Table 2. Principles of therapeutic responses to the problems of the patient.

\begin{tabular}{lll}
\hline & Problems that existed before the disaster & Problems that occurred after the disaster \\
\hline $\begin{array}{l}\text { Problems caused by personal } \\
\text { circumstances }\end{array}$ & $\begin{array}{l}\text { Supportive responses } \\
\text { Psychotherapy focused on trauma and grief }\end{array}$ & $\begin{array}{l}\text { Realistic problem-solving } \\
\text { Supportive responses } \\
\text { Psychotherapy focused on trauma and grief }\end{array}$ \\
$\begin{array}{ll}\text { Problems experienced by the } \\
\text { community as a whole }\end{array}$ & $\begin{array}{l}\text { Acceptance of unresolved issues } \\
\text { Support in determining one's own attitudes toward } \\
\text { cultural realities and handling conflicts }\end{array}$ & $\begin{array}{l}\text { Realistic problem-solving } \\
\text { Acceptance of unresolved issues } \\
\text { Implementing long-term and realistic solutions }\end{array}$ \\
\hline
\end{tabular}

separation were considered, but these were rejected by the patient. Instead, trauma-focused psychotherapy was effective for 4.5. Conventional medical treatment was also given priority for 6 ("own stomach cancer"). In response to "the death of her dog" (problem 7), we considered both working on the real-life environment (e.g., getting another dog) and a psychotherapeutic approach to deal with the loss.

"The problems experienced by the community as a whole that existed before the disaster" are cultural issues, and addressing them in earnest is not possible at the individual level. What would be possible in individual clinical situations would be to consider how to respond to the problem as it materializes in one's life and to acknowledge that it is a difficult problem to change in the community in which one lives, to determine one's attitudes toward it, and to deal with the psychological conflicts associated with it. The patient had a strong tendency to accept problems 8 to 10 as natural, and rarely spoke of the conflicts associated with them. On the other hand, an important development was the change in her ability to express anger and to defend herself against her father-in-law as her treatment progressed.

In addition, the problems experienced by the community as a whole and triggered by the earthquake could be treated as a psychological problem, but before treating it as so, a practical solution to the problem should be considered. The psychological impact was then examined; in addition to supportive medical treatment for issues $11,12,14$, and 15, trauma-focused treatment for 11,12 , and 14 was also provided in the form of imaginary exposure techniques for 11,12 , and 14 during sustained exposure. With regard to problem 13, on several occasions, strong anger at TEPCO, the operator of the nuclear power plant that caused the accident, was expressed, and this was responded to in a supportive manner, assuring her that the anger was justified. Problem 16 was closely related to problem 10 and similar responses were implemented. For each issue, Table 2 summarizes the principles of therapeutic responses.

\subsection{Conflicts between strong local values and those of supporters}

As the attending physician in charge of this case, I was troubled by the fact that the patient took on the responsibility of handling the major problems in the family, which resulted in a significant loss of health. However, the entire family, including the patient herself, took it for granted that the patient should bear the burden in this way. Although it might be possible to view this situation as a "custom of disdain for women", "a trend of seniority" and "community exclusivity", the reality was very harsh. In contrast, the best course of action, derived from the values that informed clinical psychiatry, would be to encourage the patient to become more independent, specifically to get her to leave the place in the form of separation. However, that option did not seem to be considered by her at all, and I could imagine that it would not be easy for her to carry out this action in the local community. In fact, with other patients that the author has treated at the clinic, even if domestic violence was occurring at the time of the patient's visit, the probability of dropping out of treatment early was high if separation or consultation with the administration is urged to the patient at the earliest opportunity. This forces us to tolerate the patients' traditional values in the early stages of treatment, but this can lead to an ethical dilemma for the physician in charge, as it seems to allow the patient to continue to be subjected to various forms of abuse. In practice, it is important to avoid making this conflict structure manifest at least in the early stages of treatment, as in the present case. This allows time to build a trusting relationship with the patient and to have him or her gradually accept respect for basic human rights as a part of a practical therapeutic response, such as temporary refuge. The psychotherapeutic process also aims to modify the excessive fear of authority held by local elders and, within reasonable limits, to facilitate the patient's acknowledgment of his or her appropriate feelings of anger, resentment, and frustration. In this process, the establishment of a "new identity" without extremes of either of the two values emerged, in parallel with her overcoming the effects of the complicated trauma she had experienced.

\section{Conclusions}

This paper has presented a case of a woman who had been subjected to long-term physical domestic violence in her home, both before the earthquake and after it. She had frequent panic attacks and dissociative symptoms and received psychiatric treatment during a long period of evacuation. It should be noted again that the fear of direct health effects of radiation exposure was rarely mentioned by the patient. Although the patient's treatment did not begin until 3 years after the 2011 accident, it is likely that even this patient felt more fear about radiation exposure at the beginning of the accident. However, nearly a decade after the disaster, that fear seems to have become relative to the many fears she felt in her life. In terms of the effects of radiation, indirect factors such as evacuation and conflicts with others over compensation payments seem to have had a greater impact on her mental health. 
She experienced much of the distress experienced by residents of the nuclear power plant disaster area, but it was the repeated domestic violence that had the most profound effect on her. It is assumed that there is an increase in abuse and domestic violence associated with the Great East Japan Earthquake; however, few of these cases have been reported. In general, when domestic violence is still ongoing, the recommended response for supporters, including the attending physician, is to prioritize environmental adjustments, such as encouraging the victim to leave the home and treating the individual's symptoms. However, in the present case, the individual and those around her initially had values that made domestic violence acceptable, and strongly recommending evacuation from the home was considered to undermine trust. Under such circumstances, I treated the patient as she was in such a situation, even though I was aware that the domestic violence continued in the family, and I prioritized the improvement of her symptoms. Through the course of such treatment, the patient and her family gradually came to accept the value of viewing domestic violence as a problem, and to feel that it was right to be angry at and oppose those involved in the violence. At the same time, this also led to a change in the author's view of the need to identify and address the problem as soon as possible, which had been held by the author as a therapist and researcher. This meant that a new identity was established for the individuals involved as they worked through their own traumatic experiences and situations. The recovery of these individuals is a precondition for the community to truly recover and for consensus building to take place on important matters among residents.

\section{References}

Beck AT, Steer RA, Brown GK. 1996. BDI-II: Beck Depression Inventory Manual. 2nd ed. San Antonio, TX: Psychological Corporation.

Bromet EJ, Havenaar JM, Guey LT. 2011. A 25-year retrospective review of the psychological consequences of the Chernobyl accident. Clin. Oncol. (R. Coll. Radiol.) 23(4): 297-305. https:// doi.org/10.1016/j.clon.2011.01.501.

Bromet EJ. 2012. Mental health consequences of the Chernobyl disaster. J. Radiol. Prot. 32(1): N71-N75. https://doi.org/10.1088/ 0952-4746/32/1/N71.

Edward MK, Davis RB. 2012. Psychological first aid. In: Disaster psychiatry: readiness, evaluation, and treatment (F.J. Stoddard, A. Pandya, C.L. Katz, Eds.), pp. 203-212. Washington, DC: American Psychiatric Publishing.

van Emmerik AA, Kamphuis JH, Hulsbosch AM, Emmelkamp PM. 2002. Single session debriefing after psychological trauma: a meta-analysis. Lancet 360(9335): 766-771. https://doi.org/ 10.1016/S0140-6736(02)09897-5.

Foa EB, Kozak MJ. 1986. Emotional processing of fear: exposure to corrective information. Psychol. Bull. 99(1): 20-35.

Foa EB, Cashman L, Jaycox L, Perry K. 1997. The validation of a selfreport measure of posttraumatic stress disorder: the posttraumatic diagnostic scale. Psychol. Assess. 9: 445-451. https://doi.org/ 10.1037/1040-3590.9.4.445.

Hori A, Hoshino H, Miura I, Hisamura M, Wada A, Itagaki S, Kunii Y, Matsumoto J, Mashiko H, Katz CL, Yabe H, Niwa SI. 2016. Psychiatric outpatients after the 3.11 complex disaster in Fukushima, Japan. Ann. Glob. Health 82(5): 798-805. https:// doi.org/10.1016/j.aogh.2016.09.010.

Hori A, Takebayashi Y, Tsubokura M, Kim Y. 2019. Efficacy of PE therapy for a patient with late-onset PTSD affected by evacuation due to the Fukushima nuclear power plant accident. BMJ Case Rep. 12(12): e231960. https://doi.org/10.1136/bcr-2019-231960.

Hori A, Takebayashi Y, Tsubokura M, Kim Y. 2020. PTSD and bipolar II disorder in Fukushima disaster relief workers after the 2011 nuclear accident. BMJ Case Rep. 13(9): e236725. https://doi. org/10.1136/bcr-2020-236725.

Kukihara H, Yamawaki N, Uchiyama K, Arai S, Horikawa E. 2014. Trauma, depression, and resilience of earthquake/tsunami/nuclear disaster survivors of Hirono, Fukushima, Japan. Psychiatry Clin. Neurosci. 68: 524-533. https://doi.org/10.1111/pcn.12159.

Maeda M, Oe M. 2017. Mental health consequences and social issues after the Fukushima disaster. Asia Pac. J. Public Health 29 (2_Suppl.): 36S-46S. https://doi.org/10.1177/ 1010539516689695.

Mitchell JT. 1983. When disaster strikes. The critical incident stress debriefing process. JEMS 8(1): 36-39.

National Child Traumatic Stress Network/National Center for PTSD. 2006. Psychological first aid: field operations guide. 2nd ed. https:/www.nctsn.org/resources/psychological-first-aid-pfa-fieldoperations-guide-2nd-edition (accessed 14 Sep 2020).

North CS, Pfefferbaum B. 2013. Mental health response to community disasters: a systematic review. JAMA 310(5): 507518. https://doi.org/10.1001/jama.2013.107799.

Oe M, Fujii S, Maeda M, Nagai M, Harigane M, Miura I, Yabe H, Ohira T, Takahashi H, Suzuki Y, Yasumura S, Abe M. 2016. Three-year trend survey of psychological distress, posttraumatic stress, and problem drinking among residents in the evacuation zone after the Fukushima Daiichi Nuclear Power Plant accident [The Fukushima Health Management Survey]. Psychiatry Clin Neurosci 70: 245-252. https://doi.org/10.1111/pcn.12387.

Rahu K, Rahu M, Tekkel M, Bromet E. 2006. Suicide risk among Chernobyl cleanup workers in Estonia still increased: an updated cohort study. Ann. Epidemiol. 16(12): 917-919. https://doi.org/ 10.1016/j.annepidem.2006.07.006.

Sakuma A, Ueda I, Shoji W, Tomita H, Matsuoka H, Matsumoto K. 2020. Trajectories for post-traumatic stress disorder symptoms among local disaster recovery workers following the Great East Japan Earthquake: group-based trajectory modeling. J. Affect. Disord. 274: 742-751. https://doi.org/10.1016/j.jad.2020.05.152.

Takebayashi Y, Hoshino H, Kunii Y, Niwa SI, Maeda M. 2020. Characteristics of disaster-related suicide in Fukushima Prefecture after the nuclear accident. Crisis: 1-8. https://doi.org/10.1027/ 0227-5910/a000679.

World Health Organization. 2011. Psychological first aid: guide for field workers. Geneva: World Health Organization. https://www. who.int/mental_health/publications/guide_field_workers/en/ (accessed 14 Sep 2020).

Cite this article as: Hori A. 2020. Coming to terms with Fukushima disaster-related trauma and earlier trauma by constructing a new identity. About a case. Radioprotection 55(4): 283-290 